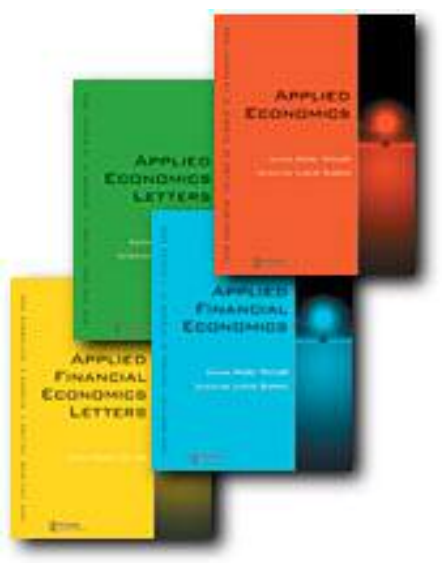

ASSESSING STICKY PRICE MODELS USING THE BURNS AND MITCHELL APPROACH

\begin{tabular}{|c|l|}
\hline Journal: & Applied Economics \\
\hline Manuscript ID: & APE-05-0692.R1 \\
\hline Journal Selection: & Applied Economics \\
\hline JEL Code: & $\begin{array}{l}\text { E30 - General < E3 - Prices, Business Fluctuations, and Cycles < E - } \\
\text { Macroeconomics and Monetary Economics, E52 - Monetary Policy } \\
\text { (Targets, Instruments, and Effects) }<\text { E5 - Monetary Policy, Central } \\
\text { Banking, and the Supply of Money and Credit }<\text { E - Macroeconomics } \\
\text { Prices, Business Fluctuations, and Cycles < E - Macroeconomics and } \\
\text { Monetary Economics, E32 - Business Fluctuations|Cycles }<\text { E3 - } \\
\text { Prices, Business Fluctuations, and Cycles }<\text { E - Macroeconomics and } \\
\text { Monetary Economics, E31 - Price Level|Inflation|Deflation }<\text { E3 - } \\
\text { Prices, Business Fluctuations, and Cycles }<\text { E - Macroeconomics and } \\
\text { Monetary Economics }\end{array}$ \\
\hline Keywords: & \begin{tabular}{l} 
New Keynesian Models, Correlations, Burns and Mitchell \\
\hline
\end{tabular} \\
\hline
\end{tabular}




\title{
ASSESSING STICKY PRICE MODELS USING THE BURNS AND \\ MITCHELL APPROACH \\ Juan Páez-Farrell ${ }^{1}$ \\ Cardiff Business School
}

\begin{abstract}
This paper evaluates sticky-price models using the methods proposed by Burns and Mitchell, focusing on the monetary aspects of the business cycle. Recent research has emphasised the responses of models to shocks at the expense of its systematic component. Whereas sticky-price models have been successful at replicating impulse response functions from VARs, this paper highlights that they are unable to mimic the data for nominal variables. Moreover, the results are robust to the specification of the Phillips curve, including its backward-looking variant, calibrated values and the inclusion of fiscal policy shocks. Since being able to mimic the data is the lowest hurdle a model must pass, these results pose a challenge for sticky price models.
\end{abstract}

\section{JEL Classification: E32, E52, E58}

Key Words: New Keynesian Models, Business Cycles, Correlations, Burns and Mitchell.

Mailing address: Economics Section, Cardiff Business School, Colum Road, CF10 3EU, tel: +44 20876566, fax: +44 20874419, paez-farrellj@cf.ac.uk. 


\title{
ASSESSING STICKY PRICE MODELS USING THE BURNS AND MITCHELL APPROACH
}

\begin{abstract}
This paper evaluates sticky-price models using the methods proposed by Burns and Mitchell, focusing on the monetary aspects of the business cycle. Recent research has emphasised the responses of models to shocks at the expense of its systematic component. Whereas sticky-price models have been successful at replicating impulse response functions from VARs, this paper highlights that they are unable to mimic the data for nominal variables. Moreover, the results are robust to the specification of the Phillips curve, including its backward-looking variant, calibrated values and the inclusion of fiscal policy shocks. Since being able to mimic the data is the lowest hurdle a model must pass, these results pose a challenge for sticky price models.
\end{abstract}

\section{JEL Classification: E32, E52, E58}

Key Words: Sticky price Models, Business Cycles, Correlations, Burns and Mitchell. 


\section{INTRODUCTION}

Beginning with Kydland and Prescott (1982) real business cycle (RBC)

macroeconomics has led to sweeping changes in the way macroeconomics is

conducted. There is greater emphasis on building models with strong

microeconomic foundations, with the aim of overcoming the Lucas critique; the

supply side was considered the economy's driving force and traditional econometric techniques were eschewed in favour of a more a-theoretical approach that attempted to construct models which were able to replicate their empirical counterparts' second moments.

The current paradigm in macroeconomics, New Keynesian macroeconomics, builds on many elements from RBC theory, but has placed greater emphasis on nominal rigidities and the nominal causes of output fluctuations - so that consequently, less importance has been attached to technology shocks - and models are often evaluated by their ability to replicate the impulse responses obtained from vector autoregressions (VARs). But this focus on the effects of shocks, to the neglect of a model's systematic components, could potentially lead researchers to incorrectly conclude that their model performs well, as only one aspect of the model's characteristics is observed. The traditional assessment procedure used to evaluate RBC models proposed by Kydland and Prescott, which built on the work of Burns and Mitchell (1946), focused on the co-movement of variables as the defining features of the business cycle. Nevertheless, this approach has been increasingly discarded due to identification problems. The purpose of this paper is to argue that the RBC model evaluation methodology can still provide useful insights and that this 
is an area that should not be neglected. Evaluating a model solely on the basis of the cross correlations it yields and the standard deviations of the variables has its limitations; simply because a model is able to mimic the data does not mean that it can explain it. As Summers (1986) argued, "Many theories can approximately mimic any given set of facts; that one theory can does not mean that it is even close to right". Indeed, in the context of RBCs, one of the biggest limitations was the ability of many models to mimic the data and the Burns-Mitchell methodology was unable to discriminate alternative models. As King and Plosser (1994) found, one cannot distinguish between a Keynesian (Klein-Goldberger) and an RBC model when using the methods of Burns and Mitchell. As a result, to this author's knowledge, there has been no general attempt to assess sticky price models using the Burns-Mitchell methodology. To the extent that alternative models are able to mimic the data, this exercise will yield few insights. However, if different model specifications result in clearly distinguishable co-movements in the variables or if the models are unable to mimic the data, then it is possible to gain additional information on the models that satisfy this minimum of benchmarks. In effect, if matching the data's co-movements is a necessary but not sufficient condition for explaining the data, then sticky price models that are unable to do so can be rejected on the grounds that they do not satisfy this basic criterion.

This paper focuses on the implications of New Neoclassical Synthesis (NNS) ${ }^{2}$ models for the behaviour of output, inflation and interest rates using RBC methods. The purpose of this paper is to determine whether different sticky price models lead

\footnotetext{
${ }^{2}$ These are defined as models embodying nominal rigidities (see Goodfriend and King, 1997), of which New Keynesian models are one variant, which assumes Calvo pricing with the resulting New Keynesian Phillips curve (equation 5 below).
} 
to clearly distinguishable co-movement in the models' variables with output, and if so, to determine which models are able to replicate the data.

The paper proceeds as follows. Section II will present the cyclical characteristics of a small subset of key macroeconomic variables for the US economy that are at the core of most small models used for monetary policy analysis, so that the theoretical models can be evaluated using RBC methods. Section III will then present a small New Keynesian (NK) macro model representative of the literature for analysing monetary policy. Section IV discusses the calibrated values used and section $\mathrm{V}$ then evaluates this benchmark model, as well as also assessing alternative variants commonly found in the literature. Section VI considers the role of fiscal policy as a source of fluctuations and section VII analyses the importance of technology shocks and operational monetary policy in sticky price business cycle models. Section VIII concludes with a discussion on the consequences of RBC analysis for sticky price models.

\section{SOME BUSINESS CYCLE FACTS}

The study of the stylised facts of economic fluctuations has already been well documented $^{3}$. Therefore this section will provide a brief description of the variables of interest, focusing on a limited number of real and nominal variables that feature prominently in modern monetary policy analysis. These are output $(y)$, the inflation rate $(\pi)$ and the nominal interest rate $(R)$. Since the relationship between real and nominal variables is likely to be unstable with changes in monetary policy regime -

\footnotetext{
${ }^{3}$ See among others, van Els (1995), Fiorito and Kollintzas (1994) and Millard, Scott and Sensier (1997).
} 
and hence the term "stylised fact" would be inappropriate - this paper will focus on the period 1987:3-2002:2, which covers Greenspan as chairman of the Fed. ${ }^{4}$ The data have been de-trended using the HP filter ${ }^{5}$ on the grounds that this paper is focusing on fluctuations of 32 quarters or less, which is exactly what the HP filter yields, as argued by King and Rebelo (2000); furthermore, using a band pass filter that discards high frequency fluctuations does not change the main conclusions of this paper.

[TABLE I]

The second column presents the standard deviation for each variable, while in the third column these are stated as a proportion of the volatility of output. $\rho_{1}$ denotes the first order autocorrelation coefficient and the remaining columns present the correlation coefficient between each variable (at time $t+i$ ) with output at date $t$. A large number in (absolute terms) appearing in column $t+i(t-i)$ indicates that the series lags (leads) the cycle by $i$ quarters. If the absolute value of the crosscorrelation is highest at $i=0$, then the variable will be defined to move contemporaneously with the cycle. Additionally, for the whole sample period the

\footnotetext{
${ }^{4}$ As in Judd and Rudebusch (1998) and Clarida, Galí and Gertler (2000), there are reasons to believe that the Fed's reaction function was stable during the Volcker-Greenspan chairmanship of the Fed.

${ }^{5}$ With a value of $\lambda=1600$.
} 
critical value for the correlation coefficients ${ }^{6}$ is 0.13 . The results from Table I indicate that all variables are procyclical, with inflation and the nominal interest rate lagging the cycle by three quarters and one quarter, respectively. Furthermore, the inflation rate displays a phase shift, as it is initially countercyclical and then procyclical.

These results are not new and well known in the RBC literature, but what has not been determined is how well sticky price models can fit these facts.

\section{A STANDARD NEW KEYNESIAN MODEL}

Most current models used for monetary policy analysis ${ }^{7}$ are derived from optimising behaviour that can be simplified into three equations. Let $y, R$ and $\pi$ denote output, a short-term nominal interest rate and inflation, respectively. $y^{f}$ represents flexible price output and $E_{t}$ is the mathematical expectations operator conditional on information up to period $t$. The shocks are given by a cost-push shock, $\xi$, a shock to the monetary policy rule, $v_{t}$ and a technology shock, $z_{t}{ }^{8}$

Then, writing the model in deviations from steady state the system is given by

$$
y_{t}=E_{t} y_{t+1}-\sigma\left(R_{t}-E_{t} \pi_{t+1}\right)
$$

\footnotetext{
${ }^{6}$ See McCandless and Weber (1995) or Hoel (1954). The standard deviation of the correlation coefficient can be computed as: $(n-3)^{-\frac{1}{2}}$, where $n$ is the sample size.

${ }^{7}$ Representative among these are Walsh (2003, Ch. 5), Galí (2003) and McCallum and Nelson (1999a).

${ }^{8}$ Both the cost-push and monetary policy shocks are assumed to be i.i.d disturbance with constant variance, whereas the technology shock is assumed to follow an $\mathrm{AR}(1)$ process.
} 
$\pi_{t}=\beta E_{t} \pi_{t+1}+\phi_{1} x_{t}+\xi_{t}$

$R_{t}=\left(1-\mu_{3}\right)\left[\mu_{1} \pi_{t}+\mu_{2} x_{t}\right]+\mu_{3} R_{t-1}+v_{t}$

$y_{t}^{f}=\left[\frac{\sigma(1+\eta)}{\sigma(1-\alpha+\eta)+\alpha}\right] z_{t}$

$x_{t}=y_{t}-y_{t}^{f}$

where $\sigma>0, \beta \in(0,1), \phi_{1}>0,0 \leq \mu_{2}, 0 \leq \mu_{3}$ and $1<\mu_{1} . \alpha$ is labour's share of income in a Cobb-Douglas production function and $\eta^{-1}$ represents the intertemporal elasticity of labour supply. ${ }^{9}$

Equation (1) represents an expectational IS equation, relating output to its expected future value and depends negatively on the rate of interest, ${ }^{10}$ with the parameter $\sigma$ being an index of the curvature of the utility function and in this case - since output equals consumption - also represents the interest elasticity of aggregate demand. Equation (2) is the New Keynesian Phillips curve derived from Calvo (1983) pricing. Current period inflation depends on expected future inflation, the output gap $^{11}$ and the cost-push shock, with $\beta$ being the subjective time preference factor. This Phillips curve formulation is the most widely used due to its tractability and

\footnotetext{
${ }^{9}$ A lucid discussion on the importance of intertemporal substitution of labour supply in business cycle analysis is provided by Blanchard and Fischer (1989, p. 338).

${ }^{10}$ Assuming that money enters the utility function in separable form has the consequence that the quantity of money can be ignored in the present model.

${ }^{11}$ In principle the NK Phillips curve would relate inflation to real marginal costs, but in the absence of endogenous state variables, as in the present model, there is a one-to-one correspondence between the output gap and real marginal costs, so one can use the former directly.
} 
microeconomic foundations, but as it has been subject to substantial criticism alternatives will also be discussed below.

Equation (3) represents the monetary policy rule, which is assumed to follow a Taylor rule with persistence, as estimated by McCallum and Nelson (1999b). The central bank raises interest rates in response to the inflation rates being above its target and the output gap, and there is also dependence on past interest rates as generally found in empirical evidence. ${ }^{12}$ A rule of this type could originate from the central bank possessing a quadratic loss function with the inflation and output gaps as its arguments - as used by e.g., Woodford (2001) - . Mayer (2003) has criticised loss functions of this form because of its symmetrical treatment of above target output and below target inflation as losses, but if this is what many central banks do follow under an inflation targeting regime ${ }^{13}$ and one assumes that the Fed's behaviour is not that different from inflation targeting central banks, the quadratic loss function remains a useful approximation. The result of a rule such as (3)in the presence of an expectational Phillips curve is that the monetary authorities face a 'Taylor menu' as defined by Uhlig (2001), that is, the central bank faces a trade off between the volatility of inflation and the volatility of the output gap. ${ }^{14}$ Equation (4) describes the behaviour of the flexible price level of output as a function of the technology shock, $z$, and is also affected by the model's parameters $\sigma, \alpha$ and $\eta$, the reason being that a technology shock not only raises flexible price output via its direct effect on the production function, but also induces

\footnotetext{
${ }^{12}$ See for example, Clarida et al (2000).

${ }^{13}$ For example, the Bank of England's target is in symmetrical with a target of $2 \%$ for the inflation rate.

${ }^{14}$ Cobham et al (2004) calculate this menu for a variety of developed economies.
} 
increases in employment through the effects on the real wage. It is also assumed that technology follows an $\mathrm{AR}(1)$ process:

$z_{t}=\rho_{z} z_{t-1}+\varepsilon_{z t} \quad \rho_{z} \in[0,1)$

and $\varepsilon_{z t}$ is assumed to be i.i.d.with mean zero and variance $\sigma_{z}^{2}$.

Equation (5) defines the output gap that is, the difference between cyclical output and its flexible price counterpart and it is one of the key variables of the model, entering the Phillips curve and being one of the target variables in the monetary policy rule. It is important to note that the monetary authority reacts to the gap between sticky-price output and its flexible-price counterpart, rather than cyclical output itself. The fact that central banks are aware of this distinction is evident in their publications and speeches where high productivity growth is not regarded as inflationary, ${ }^{15}$ so that the use of this concept can be deemed as appropriate. One should also note that there are three shocks in this model. Technology shocks, $z_{t}$, affect potential output and therefore have a direct effect on the Phillips Curve and the monetary policy rule. Additionally, there are monetary policy shocks, $v_{t}$, and cost-push shocks $\left(\xi_{t}\right)$, both i.i.d. These are important in that they provide a theoretical rationale for the existence of a short term trade-off between inflation and output stabilisation, even if it is not clear how this shock originates in the model.

\footnotetext{
${ }^{15}$ For a discussion on this issue from a central bank perspective see ECB (2000).
} 
A further issue that needs mention is the stability and uniqueness of the equilibrium in the model. These are considered at length by McCallum $(1983,2003)$ and Bullard and Mitra $(2002,2005)$ for models such as that presented above, which incorporate a monetary policy rule. The model is solved using the minimum state variable (MSV) solution, which is unique by construction, ${ }^{16}$ and Bullard and Mitra (2005) demonstrate that for monetary policy rules with inertia a stationary equilibrium exists as long as $\mu_{2}$ is small and $\mu_{1}>1$ but not too large; for the values estimated by McCallum and Nelson (1999b) this is indeed the case. To prove this, the statespace representation of the model comprised of the benchmark model presented above is:

$\left[\begin{array}{l}\pi_{t} \\ y_{t} \\ R_{t}\end{array}\right]=m R_{t-1}+q\left[\begin{array}{l}z_{t} \\ v_{t} \\ \xi_{t}\end{array}\right]$

Using the calibrated values in section IV, $m$ is given by:

$$
m=\left[\begin{array}{l}
-0.07 \\
-0.6043 \\
0.5849
\end{array}\right]
$$

which is indeed stable.

\section{CALIBRATION}

\footnotetext{
${ }^{16}$ As a result, all the models can be solved as functions of the four shocks and the lagged interest rate only, as there are no endogenous state variables present. Given that the shocks are all stationary, stability of the equilibrium requires focus on the behaviour of interest rates.
} 
The calibrated values are shown in Table II and these are standard in the NK literature, where $\rho_{z}$ and $\sigma_{z}$ are equal to 0.95 and 0.007 , respectively; $\sigma$ is set at 0.4 as in McCallum (2001a) and justifiable on the grounds that this model includes both consumption and investment. $\theta$ (the elasticity of demand) has been set at $6^{17}$ and the volatility of the cost-push shock is the same as in McCallum (2001a). The values for $\sigma_{v}, \mu_{1}, \mu_{2}$ and $\mu_{3}$ correspond to those in McCallum and Nelson (1999b) and $\beta$ is set to yield a value for the steady state real interest rate of $2 \%$. Finally, labour's share in income, $\alpha$, is set to $1 / 3$.

[TABLE II]

The paper will also present results for different values of $\phi_{1}{ }^{18}$, given the considerable disagreement over the specific formulation of the Phillips curve.

\section{RESULTS OF BENCHMARK MODEL AND VARIANTS}

Although the model presented above is representative of the NK literature on monetary policy analysis there is considerable disagreement on the specifics, ${ }^{19}$ especially those regarding the Phillips Curve (Fuhrer, 1997, Galí and Gertler, 1999) and the importance of technology.

\footnotetext{
${ }^{17}$ Using the alternative value of 11 (implying a markup of 1.1) does not affect the main results in this paper.

${ }^{18}$ Values of $\phi_{1}=[0.05,0.1]$, often used in the literature were considered, but these do not alter the main conclusions of the paper. These results are available from the author on request.

${ }^{19}$ See McCallum (2001a) for a lucid discussion of some of the issues.
} 
This section will assess New Neoclassical Synthesis $(\mathrm{NNS})^{20}$ models using three different variants, with each model being denoted by a different suffix. All the simulated data from the models is contained in the figures, which present the dynamic cross-correlations in graphic form. Each model is simulated 253 periods, discarding the first 53 periods in order to eliminate the fact that the simulations began from the model's steady states, and 1000 simulations were conducted using the programmes available from Bennett McCallum's website.

The first model is the benchmark NK model presented above with the calibrated values described in Table II; model 2 only differs from the previous one in that the Phillips curve, equation (2) is replaced by: $:^{21}$

$$
\pi_{t}=\phi_{0} E_{t} \pi_{t+1}+\left(1-\phi_{0}\right) \pi_{t-1}+\phi_{1} x_{t}+\xi_{t}
$$

as in Fuhrer and Moore (1995), with a coefficient of 0.5 for both the backward and forward looking inflation coefficients. To contrast with the first model, model 3 embodies a predominantly backward looking Phillips Curve, ${ }^{22}$ with $\phi_{0}=0.1$. For these cases, the state-space representation ( $\left.7^{\prime}\right)$ will yield:

$$
m\left[\begin{array}{l}
R_{t-1} \\
\pi_{t-1}
\end{array}\right]=\left[\begin{array}{cc}
-0.1964 & 0.7112 \\
-1.1195 & -0.4322 \\
0.7187 & 0.2047
\end{array}\right]\left[\begin{array}{l}
R_{t-1} \\
\pi_{t-1}
\end{array}\right]
$$

for the Fuher-Moore specification (model 2) and

\footnotetext{
${ }^{20}$ In this paper the term NNS will be used to define all models embodying nominal rigidities, not just the New Keynesian Phillips curve.

${ }_{21}^{21}$ All the model variants are described in Appendix A.

${ }^{22}$ According to Mankiw (2001), this formulation is superior to its forward looking variant as it better represents the economy's response to monetary shocks.
} 
$m\left[\begin{array}{l}R_{t-1} \\ \pi_{t-1}\end{array}\right]=\left[\begin{array}{cc}-0.0694 & 0.9368 \\ -1.1531 & -0.9832 \\ 0.7561 & 0.2614\end{array}\right]\left[\begin{array}{l}R_{t-1} \\ \pi_{t-1}\end{array}\right]$

for the backward-looking PC (model 3). In each case the models are clearly stable. ${ }^{23}$

Figure 1 presents the autocorrelation coefficients for output, Y, which shows that all models exhibit greater persistence than found in the data and in this respect all models are virtually indistinguishable.

\section{[Figure 1]}

These results are not surprising when one considers that RBC models possess similar features and that these sticky price models have the same underlying real structure. In this regard, the main contribution of NK models is their ability to provide an account of the real effects of nominal variables, which is the emphasis of this paper.

Figure 2 presents the results for the cross correlations of output with inflation. A striking feature in all three models, including the backward looking Phillips Curve (PI3), is that they imply countercyclical inflation and moreover, it moves contemporaneously with the cycle, whereas in the data inflation is procyclical and lags the cycle. This result is stronger than that reported in Galí and Gertler (1999) ${ }^{24}$ since it applies not only to the basic NK model (PI1) where inflation is forward looking, but also in model 3, with backward-looking inflation.

${ }^{23}$ Results for all the other models considered in this paper are available from the author upon request. ${ }^{24}$ Also, they treat de-trended output as the output gap, whereas in this paper that variable would be cyclical output and the gap would be the difference between this variable and its flexible price counterpart. 
[Figure 2a]

[Figure 2b]

The results for the nominal interest rate are even more pronounced and in all cases it is clear that the models are unable to capture the dynamics of the data, even qualitatively. ${ }^{25}$ These results may seem counterintuitive, but their interpretation is straightforward. The model includes technology, cost push and monetary policy shocks. The first two lead to countercyclical inflation; that is, both move output ${ }^{26}$ and inflation in opposite directions. The monetary policy shock however, produces a procyclical relationship between the two variables.

There are two important features regarding the shocks. First, in terms of their volatility, monetary policy shocks only account for a very small proportion of total interest rate volatility, which is the reason McCallum (2001b) has argued in favour of emphasising the systematic component of monetary policy. In effect, the monetary policy shocks are small relative to the cost push and technology shocks. The second feature is the way the shocks affect the model, that is, the model's structure. The cost push shock enters the Phillips curve one-for-one; the technology shock, by having a direct effect on the output gap ${ }^{27}$ has a direct effect on inflation and on the IS part of the model, whereas the monetary policy shock affects the IS only.

\footnotetext{
${ }^{25}$ It is worth pointing out that these results are robust to changes in parameter values, as often used in the literature.

${ }^{26}$ It is important to note that this refers to cyclical output and not the output gap, which is a different concept in the present model.

${ }^{27}$ The coefficient relating the flexible price level of output to the technology shock is generally close to one for standard calibrated values.
} 
Thus for these two nominal variables, interest rates and inflation, NNS models seem unable to explain their comovement with output, in other words, the business cycle. This is surprising, given the considerable amount of research and improvements in estimating monetary policy rules and robust estimates of the Phillips Curve. So this begs the question: how should these models be modified?

\section{INCLUDING FISCAL POLICY SHOCKS}

New Keynesian models tend to emphasise monetary policy issues and the role of nominal rigidities. Allowing for the inclusion of fiscal expenditure and assuming that government expenditures follow an AR(1) process, ${ }^{28}$ the effect would be to rewrite equation (1) as:

$$
y_{t}=E_{t} y_{t+1}-\sigma \frac{C}{Y}\left(R_{t}-E_{t} \pi_{t+1}\right)+\left(1-\rho_{g}\right) \frac{G}{Y} g_{t}
$$

where $\frac{G}{Y}$ represents the steady state government expenditure-output ratio, set to 0.17. The presence of a positive government spending shock in an NNS model is to raise output and, because the flexible price level of output is not affected, this will have the effect of increasing the output gap and consequently the inflation rate, potentially overcoming the effects of the previous shocks. The models with fiscal policy are shown in Figure 3, with model 4 being the standard NK model, model 5

\footnotetext{
${ }^{28}$ This follows Canzoneri et al (2004), except that, as with output, government purchases are detrended using the Hodrick-Prescott filter. The resulting AR(1) coefficient and standard deviation of the shocks are $\rho_{g}=0.97$ and $\sigma_{g}=0.007$ respectively.
} 
including the Fuhrer-Moore Phillips curve and model 6 embodying the backward looking PC.

[Figure 3a]

[Figure 3b]

The results are consistent with the findings in Canzoneri et al (2004), whose impulse responses show that the impact of government spending shocks are negligible. This result holds despite the fact that fiscal policy shocks are as volatile as technology shocks, but the reason is clear: equation ( $\left.1^{\prime}\right)$ shows that fiscal policy influences output but is scaled by the government spending-output ratio (which in the US is small) and the shock's persistence (which is very high). Consequently, the inclusion of fiscal policy in the NNS models seems to provide very little additional insight, ${ }^{29}$ whether it is for inflation or interest rates.

However, it could be argued that the reason the results presented above are at odds with the data is not because IS shocks are too small, but because the role of technology shocks has been overstated.

\section{THE ROLE OF TECHNOLOGY SHOCKS AND OPERATIONAL MONETARY POLICY}

Ever since Kydland and Prescott (1982) argued that technology shocks were central to understanding fluctuations, many economists (e.g., Summers, 1986) have argued that the role of technology has been overstated. More recently, Galí $(1999,2003)$ has argued that technology shocks are much smaller than generally estimated. Could this

${ }^{29}$ Including investment as in Canzoneri et al (2004) does not change this result. 
provide an explanation for the puzzles above? Taking the approach to an extreme, one could explore the effects of eliminating technology shocks altogether and this forms our third variant. Again, the three alternative NNS model specifications are presented in Figure 4 and the results remain largely unchanged. It is worth pointing out that model 7, embodying the NK Phillips curve, yields a slightly positive correlation coefficient between inflation and cyclical output but this improvement is counteracted by its worsening performance regarding the behaviour of the nominal interest rate, as its countercyclicality is now more pronounced. The reasoning behind this is straightforward: the source of the procyclicality of inflation in this model lies in the monetary policy shock being the driving for of the business cycle, consequently this will result in the interest being countercyclical as the monetary authority, rather than reacting to the cycle, is actually causing it.

[Figure 4a]

[Figure 4b]

Nevertheless, the values for inflation remain too low, and part of the reason for this is that ignoring technology shocks results in a greater emphasis of the cost-push shocks. ${ }^{30}$ Hence it seems that in order to capture the cyclical properties of the data, it is necessary to focus not only on the shocks and their magnitudes, but also the models' structure. In this sense, one element that has been ignored until now is the operationality of monetary policy, that is, in setting interest rates the monetary

\footnotetext{
${ }^{30}$ As is well known the inclusion of these shocks is often essential for NNS models if these are to argue that there is a tradeoff between output and inflation stabilisation.
} 
authorities do not have up to date information on the current inflation rate and output gap. ${ }^{31}$ Therefore it should be their expected values that should enter the policy rule. McCallum and Nelson (1999b) estimated equation (3) as:

$$
R_{t}=\left(1-\mu_{3}\right)\left[\mu_{1} E_{t-1} \pi_{t}+\mu_{2} E_{t-1} x_{t}\right]+\mu_{3} R_{t-1}+v_{t}
$$

This will result in monetary policy not being able to respond contemporaneously to events (and therefore, agents' expectations of changes in interest rates), and the models' cyclical behaviour is now markedly different to those presented earlier. Neglect of operationality in monetary policy is of substantial importance, ${ }^{32}$ especially when trying to determine optimal monetary policy. The results, shown in Figure 5a, demonstrate the effect of operationality on the dynamics of inflation where, to emphasise the main results of this paper, technology shocks have been omitted.

[Figure 5a]

[Figure 5b]

The model with the NK Phillips curve (PI10) is again the closest when it comes to mimicking the dynamic behaviour of inflation, and this case it is vastly superior to all the previous alternatives considered. Inflation is now procyclical and, unlike in the data, it moves contemporaneously with the cycle. Moreover, the magnitude of the correlation coefficient is lower throughout most of the cycle than its empirical

\footnotetext{
${ }^{31}$ Issues of uncertainty about the output gap is ignored in this paper.

${ }^{32} \mathrm{See}$, for example, the arguments put forward by McCallum (1997).
} 
counterpart. Nevertheless, it is able to replicate the broad features present in the data. But this improvement in the model's performance has its drawback in the performance of the nominal interest rate, as shown in Figure $5 \mathrm{~b}$-which presents the co-movement of output with interest rates- shows that NNS models still fail dismally. Hence, it is not clear that the model with operational monetary policy is superior. Moreover, given that the monetary policy rule used in this paper is an estimated one and representative of those commonly used in the literature, this truly represents a challenge for NNS models.

\section{CONCLUSION}

Modern macroeconomics emphasises a model's response to shocks compared to that of a VAR when assessing its performance. Although this approach has yielded many useful insights, it has neglected to consider the implications pertaining to the systematic components of the models.

This paper has tried to determine to what extent NNS models are capable of capturing the cyclical comovements in the data, especially with regards to nominal variables. It has done so by using the Burns-Mitchell methodology proposed by Kydland and Prescott (1982) to a variety of NNS models, using both calibrated and estimated values commonly used in the literature. The result has been that these models have limited success at replicating the data. Indeed, in many cases they imply behaviour of inflation and interest rates completely at odds with their empirical counterparts. This is surprising for two reasons. Firstly, the Burns-Mitchell 
methodology has partly been neglected when analysing real business cycles because several different models could replicate the data, so one would expect a similar conclusion to be reached for an NNS model. Secondly, NNS models have been designed to explain monetary phenomena, so their inability to describe the behaviour of inflation and interest rates is surprising.

The model that best describes the cyclical behaviour of inflation is model 10 , that is, a NK model with operational monetary policy and with no technology shocks. However, this result is obtained at the expense of strongly counterfactual implications for the nominal interest rate (the contemporaneous correlation coefficient between output and inflation is -1 .

Following Summers (1986), one should reject models that are unable to replicate the data, but being able to "mimic the facts" does not imply that a model can explain it; that is, it is a necessary but not sufficient criterion. Following this argument, since the NNS models considered above cannot replicate the data this poses a serious challenge to the New Keynesian paradigm.

An additional conclusion that emerges from the results in this paper is that by analysing both a model's systematic components and their response to shocks provides further insights and understanding of the model, whereas simply focusing on shocks can result in models that face serious shortcomings.

\section{ACKNOWLEDGEMENTS}


I am grateful to Max Gillman, Patrick Minford, Laurence Copeland and seminar participants at Cardiff Business School, the Bank of England and the Money, Macro and Finance Conference for many helpful comments. All errors are my own.

\section{REFERENCES}

Blanchard, O. J. and Fischer, S. (1989) Lectures on macroeconomics, MIT Press, Cambridge, Massachusetts.

Bullard, J. and Mitra, K. (2002) Learning about monetary policy rules, Federal Reserve Bank of St. Louis Working Paper 2000-001E.

Bullard, J. and Mitra, K. (2005) Determinacy, learnability and monetary policy inertia, Federal Reserve Bank of St. Louis Working Paper, 2000-030C.

Burns, A. F. and Mitchell, W. C. (1946) Measuring business cycles. New York, National Bureau of Economic Research.

Calvo, G. A. (1983) Staggered prices in a utility maximising framework, Journal of Monetary Economics, 12(3), 383-98.

Canzoneri, M. B., Cumby, R. E. and Diba, B. T. (2004) Price and wage inflation targeting: variations on a theme by Erceg, Henderson and Levin, mimeo.

Clarida, R., Galí, J. and Gertler, M. (1999) The science of monetary policy: a new Keynesian perspective. Journal of Economic Literature, Vol. XXXVII, December, 1661-1707.

Clarida, R., Galí J. and Gertler, M. (2000) Monetary policy rules and macroeconomic stability: evidence and some theory, The Quarterly Journal of Economics, vol. 115, 147-180. 
Cobham, D., MacMillan, P. and McMillan, D. G. (2004) The inflation variability trade-off: further evidence, Applied Economics Letters, 11, 347-350.

Els, P. J. A. van, (1995) Real business cycle models and money: a survey of theories and stylised facts. Weltwirtschaftliches Archiv, 131, 223-263.

European Central Bank. (2000) Monthly Bulletin. October, Frankfurt.

Fiorito, R. and Kollintzas, T. (1994) Stylised facts of business cycles in the G7 from a real business cycle perspective, European Economic Review, 38, 235-269.

Fuhrer, J. F. (1997) The (un)importance of forward-looking behaviour in price specifications, Journal of Money, Credit and Banking, 29 (3), 338-350.

Fuhrer, J. F. and Moore, G. R. (1995) Inflation persistence, Quarterly Journal of Economics 111(1), 127-59.

Galí, J. (1999) Technology, Employment and the business cycle: do technology shocks explain aggregate fluctuations?, American Economic Review, 89 (1), 249-271.

Galí, J. (2003) New perspectives on monetary policy, inflation and the business cycle, in Advances in Economic Theory (Ed.) M. Dewatripont, L. Hansen and S. Turnovsky, Vol. III, Cambridge University Press.

Galí, J. and Gertler, M. (1999) Inflation dynamics: a structural econometric analysis, Journal of Monetary Economics, (44), 195-222.

Goodfriend, M. and King, R. G. (1997). The New Neoclassical Synthesis and the role of monetary policy, National Bureau of Economic Research Macroeconomics Annual, . 231-95.

Hoel, P. G. (1954) Introduction to mathematical statistics, New York: Wiley. 
Judd, J. P., and Rudebusch, G. D. (1998) The Taylor rule and the Fed: 1970-1997, Federal Reserve Bank of San Francisco Economic Review, 3,. 1-16.

King, R. G. and Plosser, C. I. (1994) Real business cycles and the test of the Adelmans, Journal of Monetary Economics 33, 405-438.

King, R. G. and Rebelo, S. (2000) Resuscitating real business cycles. NBER Working Paper No. 7534.

Kydland, F. E. and Prescott, E. C. (1982) Time to build and aggregate fluctuations, Econometrica, 50 (6), 1345-1370.

McCallum, B. T. (1983) On non-uniqueness in rational expectations models: an attempt at perspective, Journal of Monetary Economics, 11, 139-168.

McCallum, B. T. (1997) Issues in the design of monetary policy rules, NBER Working Paper No. 6016.

McCallum, B. T. (2001a) Should monetary policy respond strongly to output gaps?, American Economic Review Papers and Proceedings, 91, 258-262.

McCallum, B. T. (2001b) Analysis of the monetary transmission mechanism: methodological issues, in The Monetary Transmission Process: Recent Developments and Lessons for Europe (Ed.) Deutsche Bundesbank, Palgrave Publishers.

McCallum, B. T. (2003) The unique minimum state variable RE solution is E-stable in all well formulated linear models. National Bureau of Economic Research Working Paper no. 9960. 
McCallum, B. T. and Nelson, E. (1999a) An Optimising IS-LM specification for monetary policy and business cycle analysis, Journal of Money, Credit and Banking, 31(3), 296-316.

McCallum, B. T. and Nelson, E. (1999b) Performance of operational policy rules in an estimated semiclassical structural model, in Monetary Policy Rules (Ed.) John B. Taylor, National Bureau of Economic Research Studies in Business Cycles, University of Chicago Press.

McCandless, G. T. and Weber, W. (1995) Some monetary facts, Federal Reserve Bank of Minneapolis Quarterly Review, 19 (3), 2-11.

Mankiw, N. G. (2001) The inexorable and mysterious tradeoff between inflation and unemployment, The Economic Journal, 111, C45-C61.

Mayer, T. (2003) The macroeconomic loss function: a critical note, Applied Economics Letters, 10, 347-349.

Millard, S., Scott, A. and Sensier, M. (1997) The labour market over the business cycle: can theory fit the facts? Oxford Review of Economic Policy, 13 (3), 70-92.

Summers, L. H. (1986) Some skeptical observations on real business cycle theory, Federal Reserve Bank of Minneapolis Quarterly Review, 10 (4), 23-27.

Uhlig, H. (2001) The role of national central banks and of different policy cultures, in The Impact of EMU on Europe and the developing countries (Ed.) C. Wyplosz, WIDER Studies in Development Economics, Oxford University Press, 2001. 
Walsh, C. (2003) Monetary theory and policy, Second Edition. Cambridge, MA: MIT Press.

Woodford, M. (2001) The Taylor rule and optimal monetary policy. American Economic Review, 91(2), 232-237.

\section{Appendix A: Model descriptions.}

Model 1: Basic New Keynesian Model described in the text, with $\kappa=0.05$.

Model 2: Basic NNS model with Fuhrer-Moore Phillips Curve.

Model 3: Basic NNS model with predominantly backward-looking Phillips Curve.

Model 4: NK model with fiscal policy shocks.

Model 5: Fuhrer-Moore model with fiscal policy shocks.

Model 6: Backward-looking PC with fiscal policy shocks.

Model 7: NK model with fiscal policy shocks and without technology shocks.

Model 8: Fuhrer-Moore model with fiscal policy shocks and without technology shocks.

Model 9: Backward-looking PC with fiscal policy shocks and without technology shocks.

Model 10: NK Model with operational monetary policy.

Model 11: Fuhrer-Moore model with operational monetary policy.

Model 12: Backward looking PC operational monetary policy. 
TABLE I

US BUSINESS CYCLE FACTS (1987:3-2002:2)

\begin{tabular}{|c|c|c|c|c|c|c|c|c|c|c|c|c|}
\hline Variable & $\sigma_{\mathrm{x}}$ & $\sigma_{x} / \sigma_{y}$ & $\rho 1$ & $\mathrm{t}-4$ & $\mathrm{t}-3$ & $\mathrm{t}-2$ & $\mathrm{t}-1$ & $\mathrm{t}$ & $\mathrm{t}+1$ & $\mathrm{t}+2$ & $\mathrm{t}+3$ & $\mathrm{t}+4$ \\
\hline$y$ & 0.96 & 1 & .88 & .30 & .51 & .73 & .88 & 1 & .88 & .73 & .51 & .30 \\
\hline$\pi$ & 1.02 & 1.03 & .60 & -.16 & -.08 & .00 & .17 & .23 & .35 & .34 & .38 & .34 \\
\hline$R$ & 1.87 & 1.95 & .96 & .10 & .21 & .34 & .46 & .56 & .61 & .58 & .51 & .4 \\
\hline
\end{tabular}

Table II Calibrated Values

\begin{tabular}{llll}
\hline$\phi_{0}=0.5$ & $\phi_{1}=0.05$ & $\rho_{z}=0.95$ & $\sigma_{z}=0.007 ;$ \\
$\beta=0.995$ & $\alpha=0.3$ & $\sigma_{\xi}=0.002$ & $\sigma_{v}=0.0017$ \\
$\sigma=0.4$ & $\theta=6$ & $\mu_{1}=1.5$ & $\mu_{2}=0.1$ \\
$\mu_{3}=0.8$ & $\eta=1$ & $C / Y=0.83$ & $G / Y=0.17$ \\
\hline
\end{tabular}

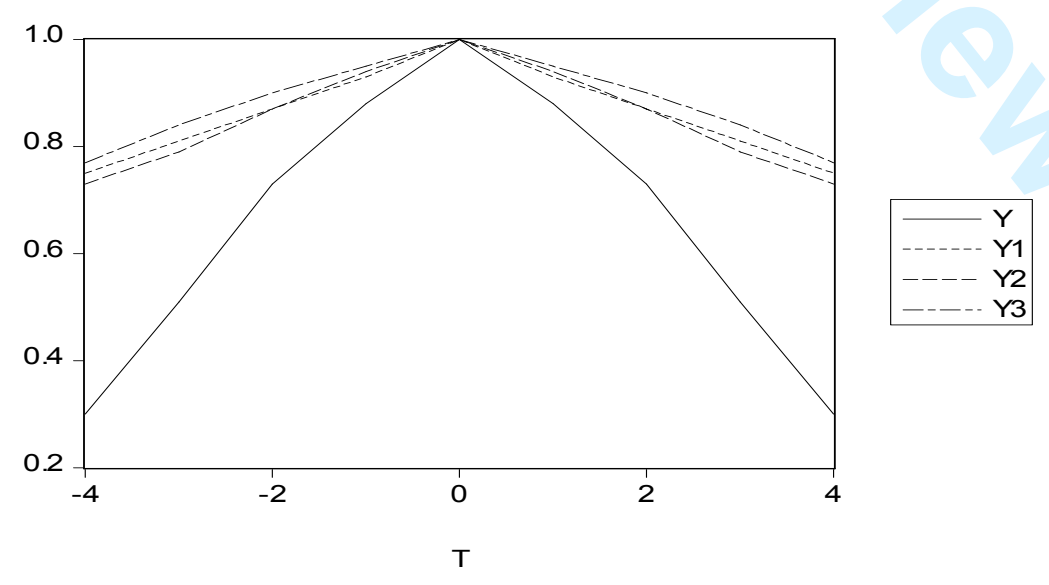

Fig. 1. Dynamic cross-correlations for output. Y represents actual GDP. Each suffix denotes a different model, described in Appendix A. 


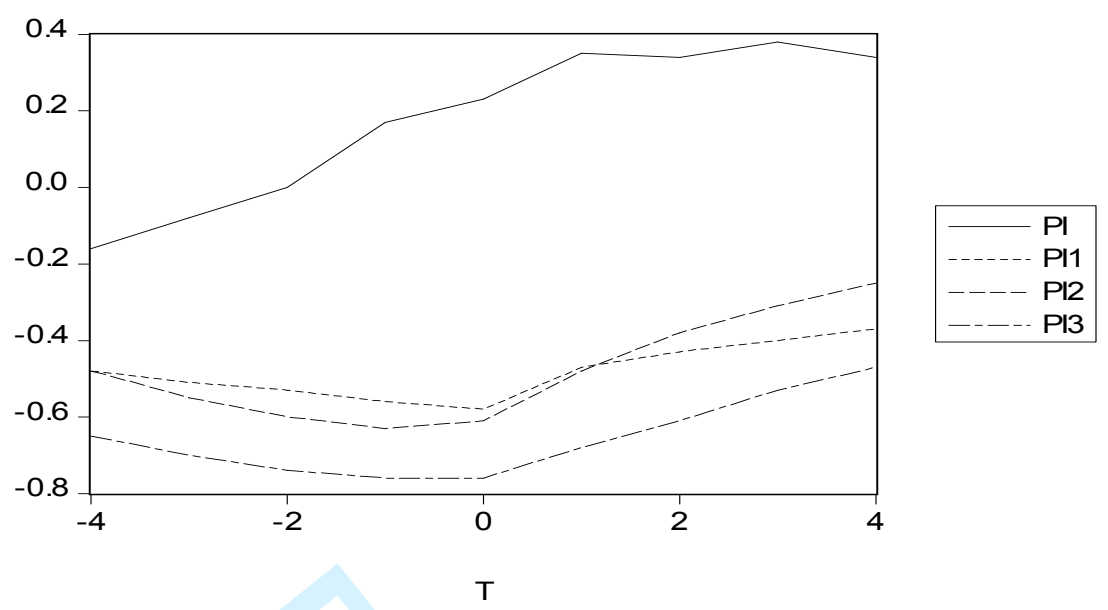

Fig. 2a. Dynamic cross-correlation between inflation at different leads and lags with output in the basic NNS model with alternative Phillips Curve specifications. PI denotes actual inflation. Each suffix denotes a different model, described in Appendix A.

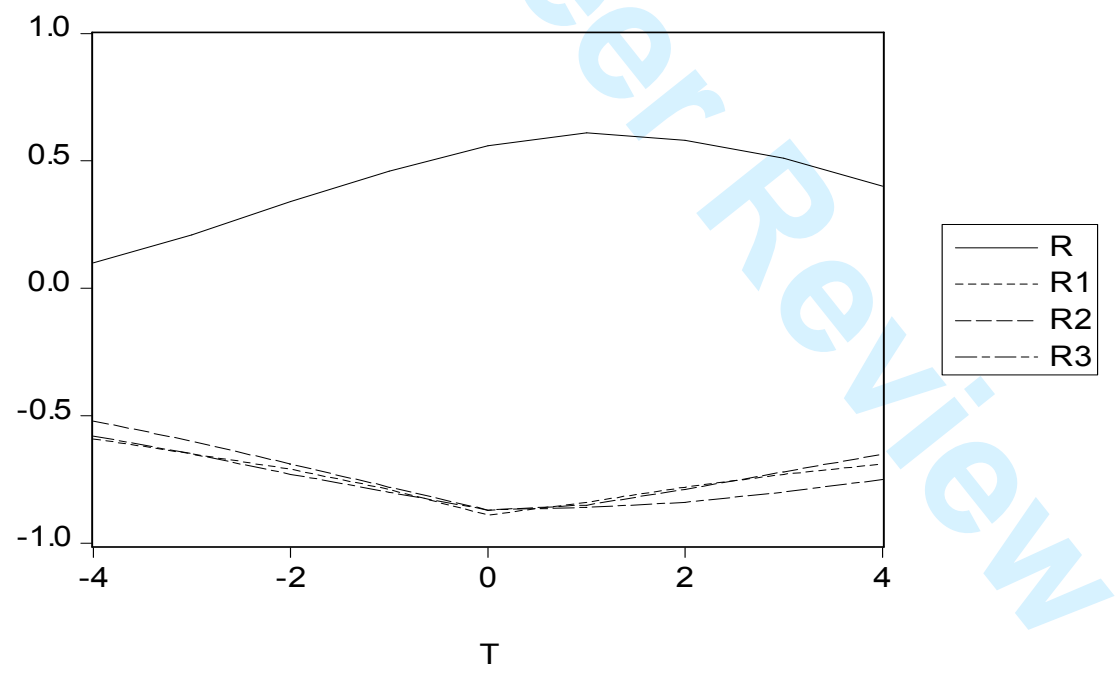

Fig. 2b. Dynamic cross-correlation between interest rates at different leads and lags with output in the basic NNS model with alternative Phillips Curve specifications. $R$ denotes the actual interest rate (Federal Funds rate). Each suffix denotes a different model, described in Appendix A. 


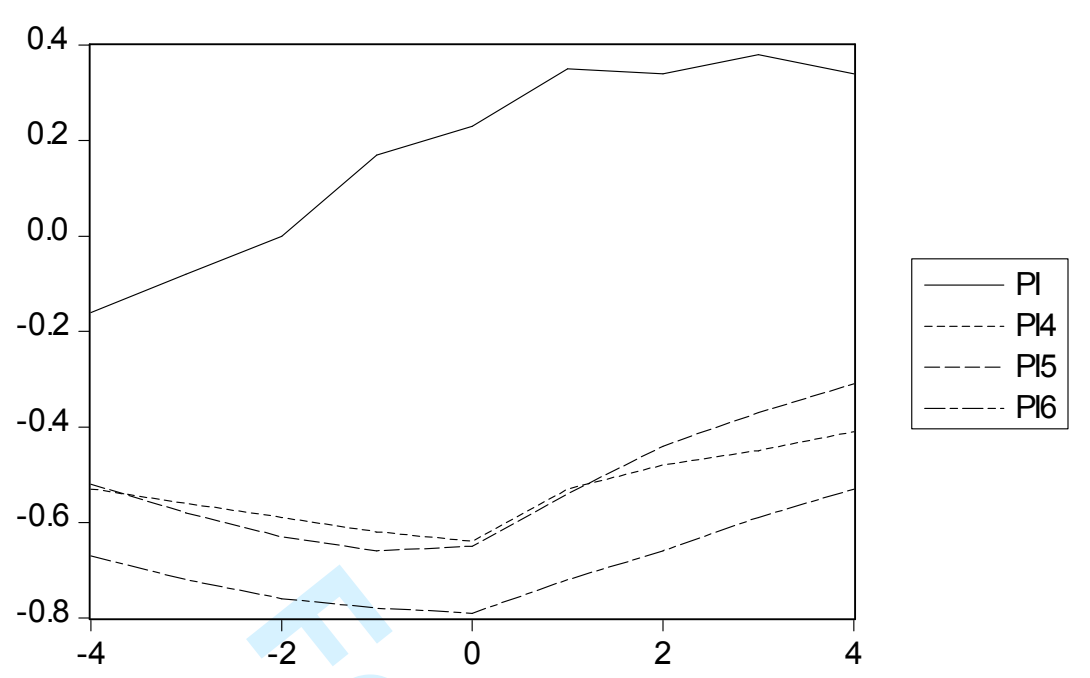

$\mathrm{T}$

Fig. 3a. Dynamic cross-correlation between inflation at different leads and lags with output in the NNS model with fiscal policy shocks. PI denotes the actual inflation rate. Each suffix denotes a different model, described in Appendix A.

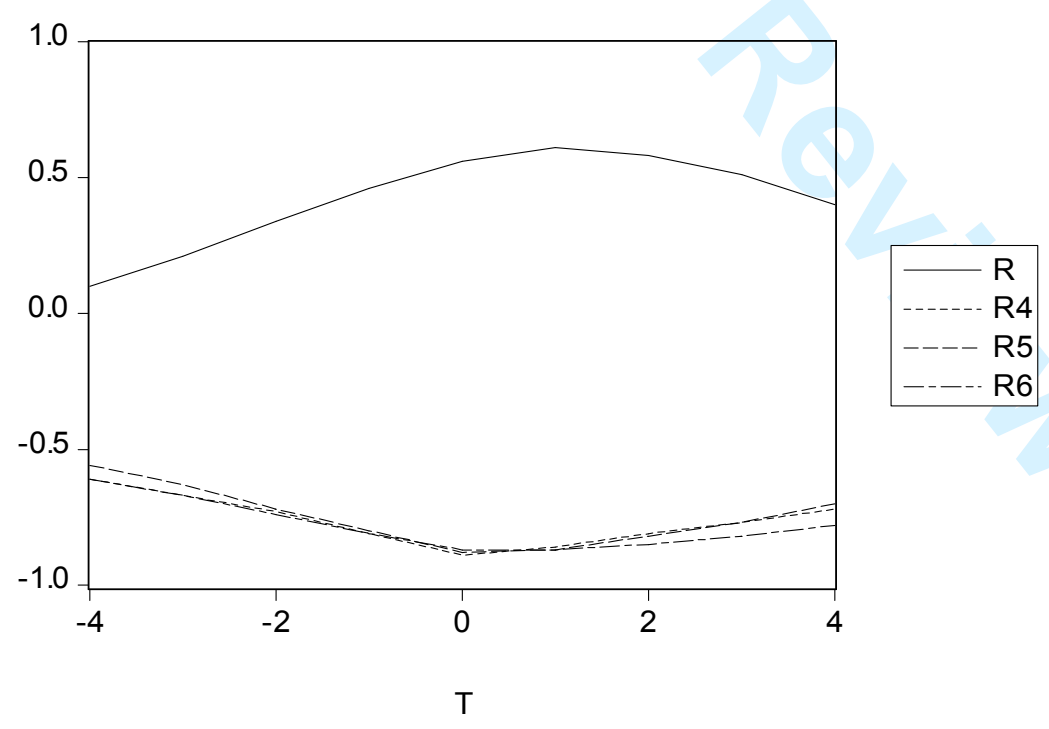

Fig. 3b. Dynamic cross-correlation between interest rates at different leads and lags with output in the NNS model with fiscal policy shocks. $R$ denotes the actual interest rate. Each suffix denotes a different model, described in Appendix A. 


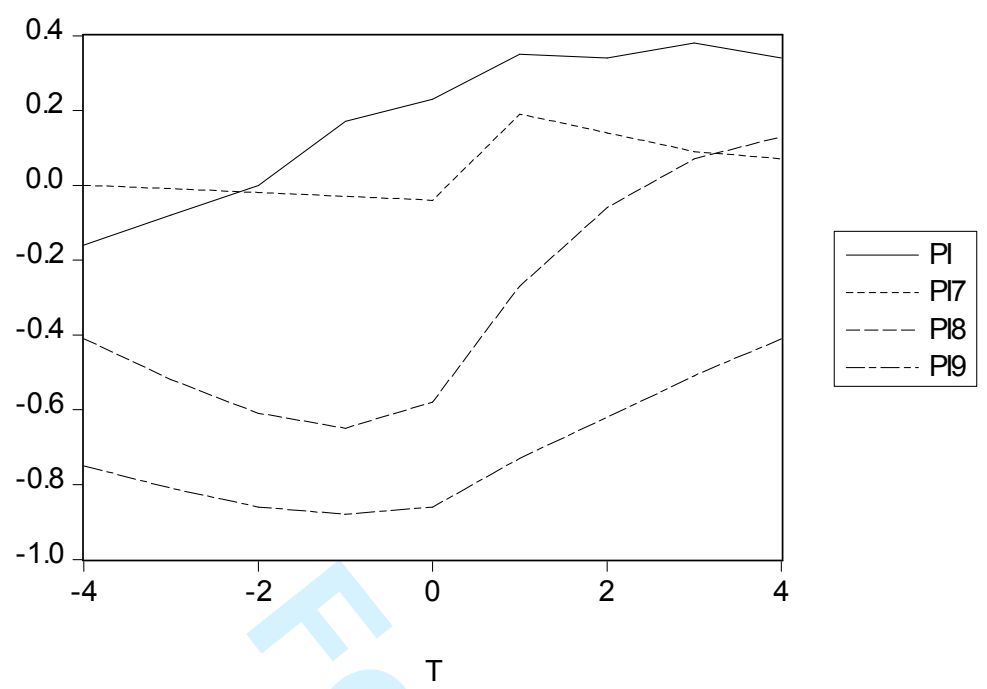

Fig. 4a. Dynamic cross-correlation between inflation at different leads and lags with output in the NNS model with fiscal policy shocks and no technology shocks. PI denotes the actual inflation rate. Each suffix denotes a different model, described in Appendix A.

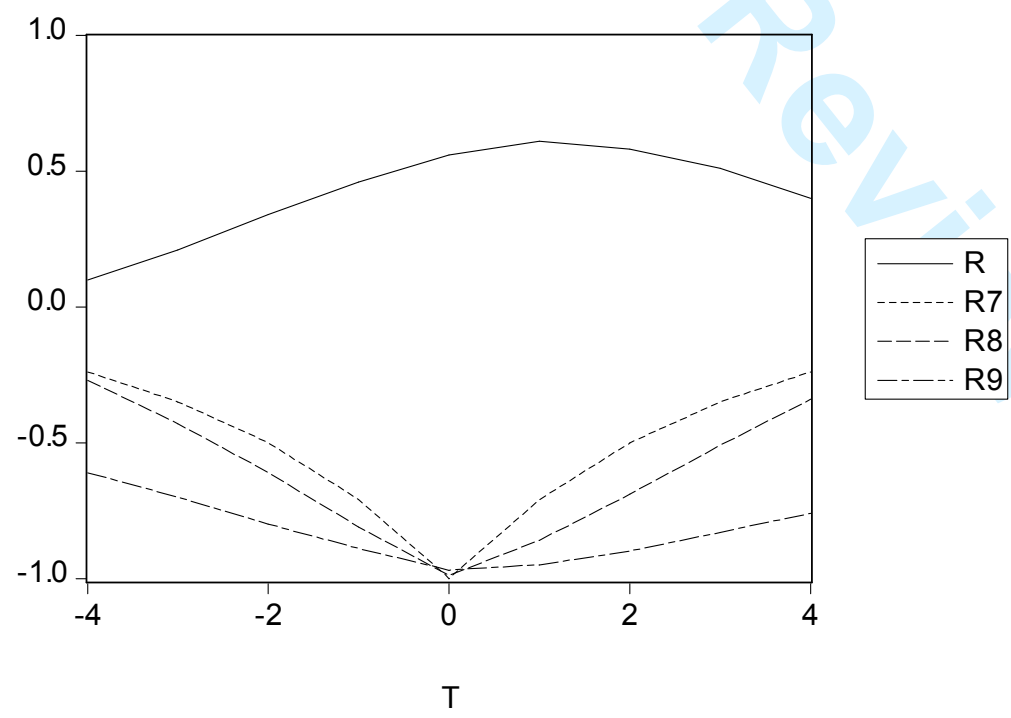

Fig. 4b. Dynamic cross-correlation between interest rates at different leads and lags with output in the NNS model with fiscal policy shocks and no technology shocks. $R$ denotes the actual interest rate. Each suffix denotes a different model, described in Appendix A. 


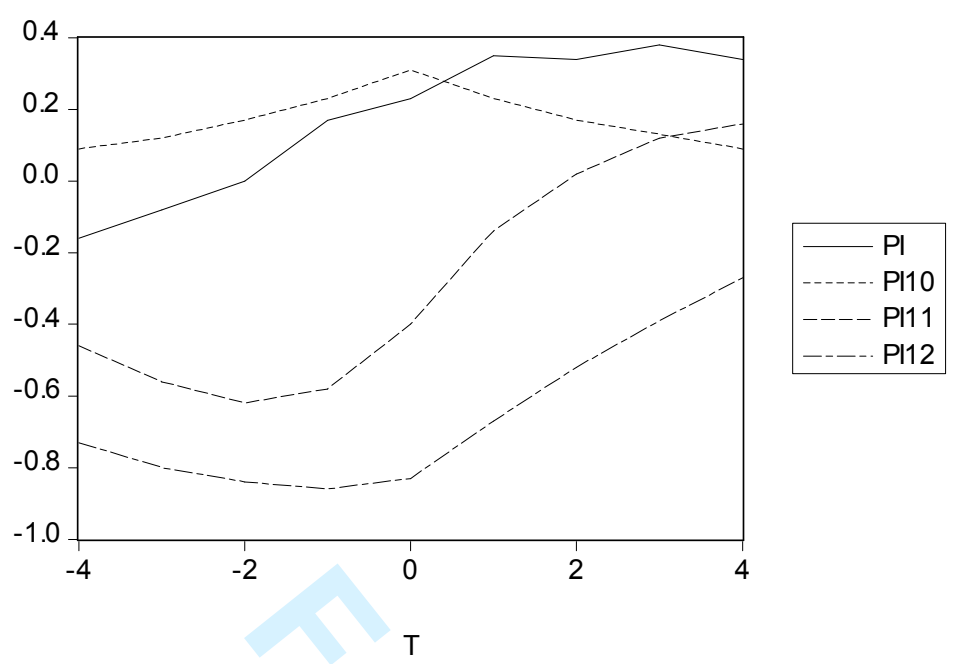

Fig. 5a. Dynamic cross-correlation between inflation at different leads and lags with output in the NNS model with fiscal policy shocks and operational monetary policy. PI denotes the actual inflation rate. Each suffix denotes a different model, described in Appendix A.

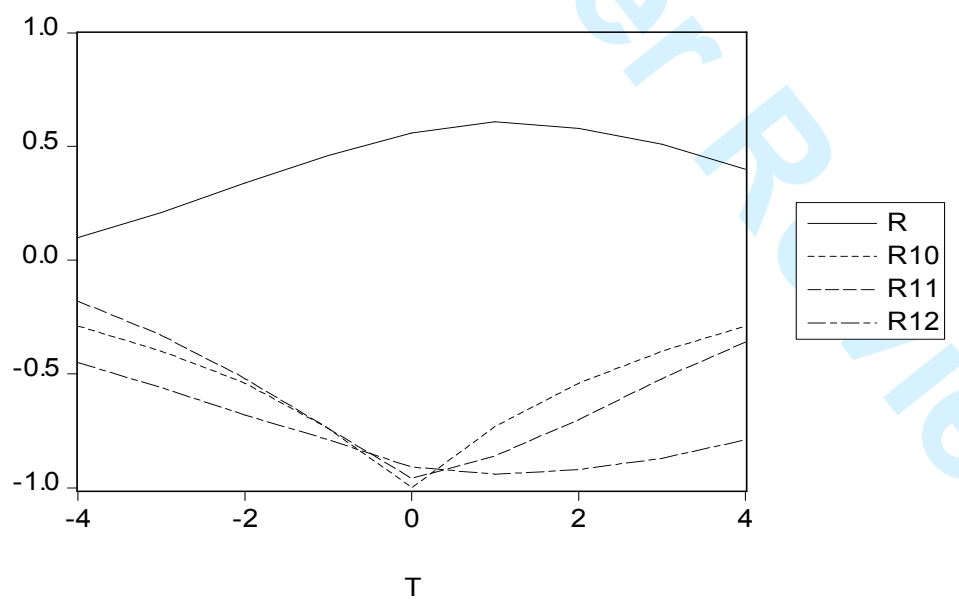

Fig. 5b. Dynamic cross-correlation between interest rates at different leads and lags with output in the NNS model with fiscal policy shocks and operational monetary policy. $R$ denotes the actual interest rate. Each suffix denotes a different model, described in Appendix A. 